\title{
The value of a chest radiograph for diagnosing a misplaced PICC line in the persistent left-sided superior vena cava
}

\author{
Dhiraj Joshi, Nicholas Ridley, Atique Imam
}

Department of Clinical Radiology, Great Western Hospital NHS Foundation Trust, Swindon, Wilts, UK

\section{Correspondence to} Dr Dhiraj Joshi, dhiraj.joshi62@gmail.com

Accepted 6 June 2014
CrossMark

To cite: Joshi D, Ridley N, Imam A. BMJ Case Rep Published online: [please include Day Month Year] doi:10.1136/bcr-2014205096

\section{DESCRIPTION}

Most peripherally inserted central catheters (PICC-lines) in our institution are placed without real-time fluoroscopy. However, every patient has a completion chest radiograph, which is reported by a radiologist to confirm the tip of the PICC-line in the superior vena cava. Any deviation from the desired position is rectified.

A 42-year-old woman had a PICC-line insertion in her left arm. The chest radiograph demonstrated that the PICC-line was abnormally placed along the left mediastinal border (figure 1), contrary to its normal course into the superior vena cava along the right border (figure 1). A previous CT scan demonstrated a persistent left-sided superior vena cava (PLSVC; figure 2). It was also noted that the PLSVC drained into the left atrium (video 1).

PLSVCs are found in $0.3 \%$ of the population and $90 \%$ open normally into the right atrium

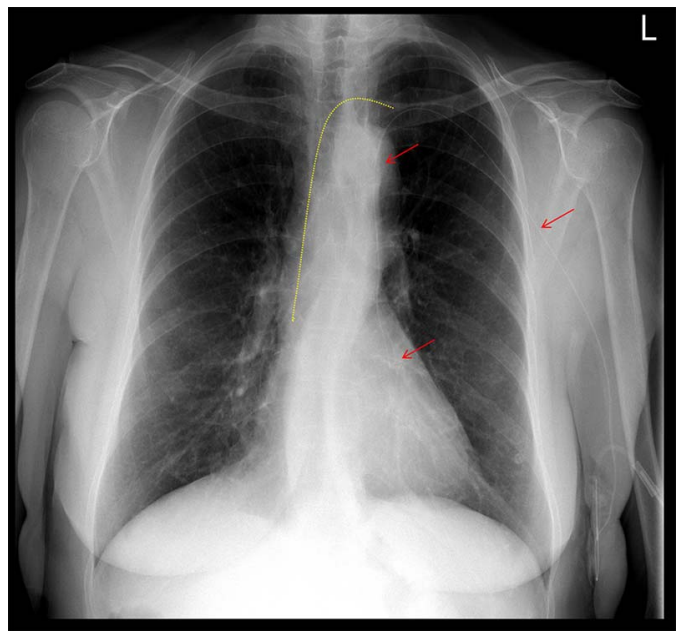

Figure 1 The frontal chest radiograph demonstrates the misplaced peripherally inserted central catheter (PICC-line; red arrows) in the persistent left superior vena cava. The yellow line shows the normal course of the PICC-line when placed in the left arm.

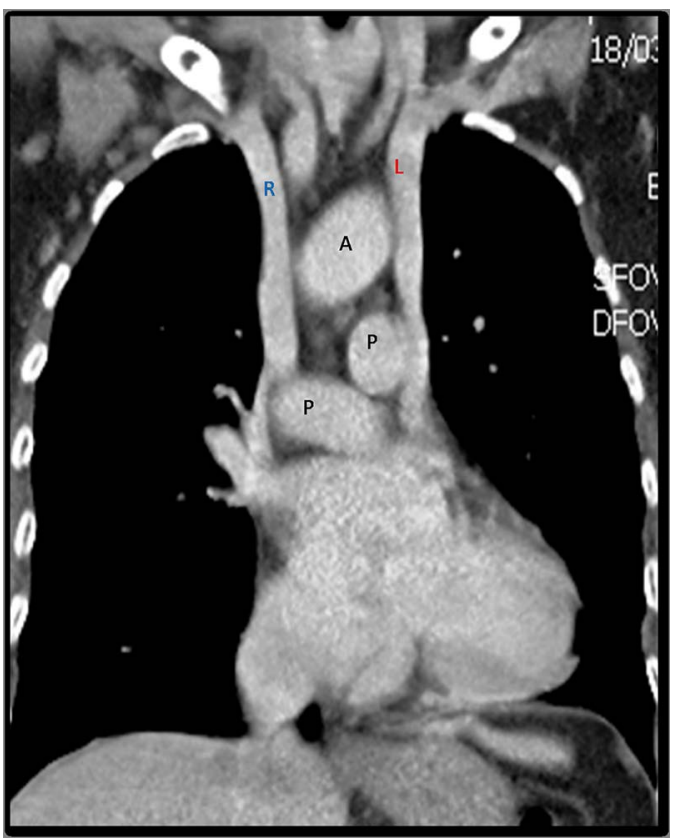

Figure 2 The coronal reformats of the contrastenhanced CT scan of the thorax that demonstrates the persistent left-sided superior vena cava $(L)(A$, aorta; $P$, pulmonary artery; $R$, right-sided superior vena cava).

through the coronary sinus; the remaining $10 \%$ (as in the index case) open into the left atrium. ${ }^{1}$ The latter group is predisposed to paradoxical embolism because the pulmonary circulation which acts as a natural filter to all emboli is bypassed. Approximately $50 \mathrm{~mL}$ air can be tolerated in the right side of the heart, whereas $0.5 \mathrm{~mL}$ of air on the left can pass directly into the systemic circulation and cause potentially fatal embolism. ${ }^{23}$

In our practise we have noted that it is difficult to completely exclude minute air bubbles from the peripherally delivered intravenous medications. Therefore, it was decided to remove the misplaced PICC-line and a tunnelled catheter was inserted on the right side. 


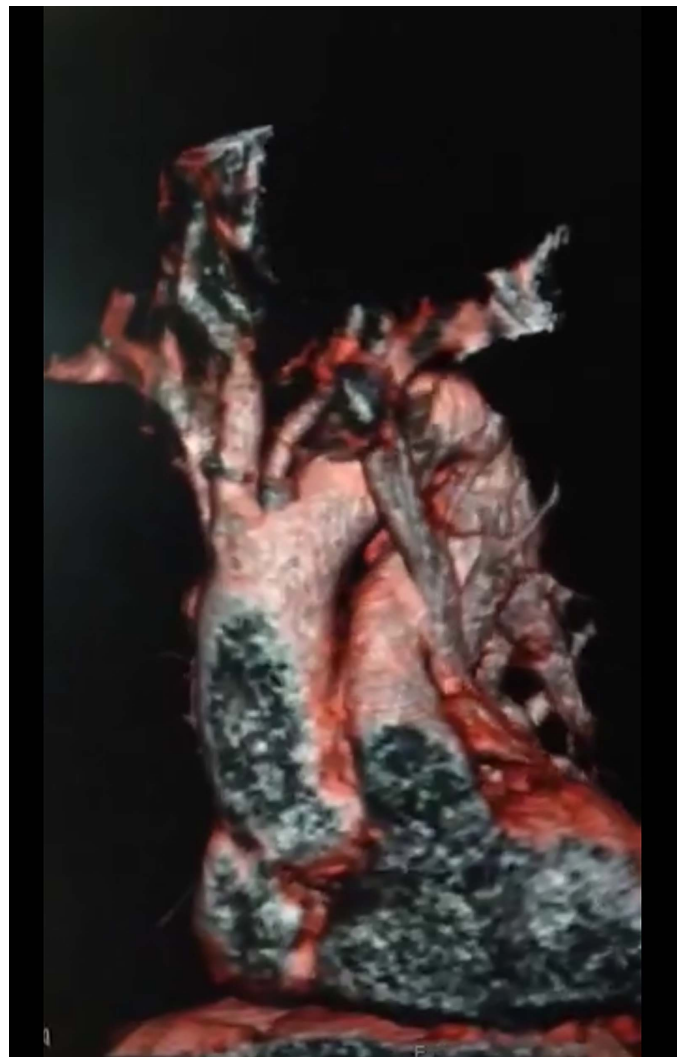

Video 1 CT scan: Three-dimensional 360 degrees volume-rendered CT scan of the heart that demonstrates the persistent left sided superior vena cava opening into the left atrium.

\section{Learning points}

- It is essential to confirm the position of the peripherally inserted central catheter line before attempting to use it. In more difficult cases real-time fluoroscopy may be used.

- If the position is abnormal a comparison with previous imaging, if available, should always be performed.

- Persistent left-sided superior vena cava, although rare, can cause transient ischaemic attacks, stroke or other potentially fatal systemic embolism from peripherally delivered intravenous medication contaminated with unwanted but often unavoidable minute air bubbles. An alternate route may be considered.

\section{Competing interests None.}

Patient consent Obtained.

Provenance and peer review Not commissioned; externally peer reviewed.

\section{REFERENCES}

1 Barba T, Karsenty J, Boussel L, et al. Brain abscess associated with persistent left superior vena cava in a 58-year-old man. BMJ Case Rep 2013;2013:pii: bcr2013009017.

2 Hutyra M, Skala T, Sanak D, et al. Persistent left superior vena cava connected through the left upper pulmonary vein to the left atrium: an unusual pathway for paradoxical embolization and a rare cause of recurrent transient ischaemic attack. Eur J Echocardiogr 2010;11:E35.

3 Povoski SP, Khabiri H. Persistent left superior vena cava: review of the literature, clinical implications, and relevance of alterations in thoracic central venous anatomy as pertaining to the general principles of central venous access device placement and venography in cancer patients. World J Surg Oncol 2011;9:173.

Copyright 2014 BMJ Publishing Group. All rights reserved. For permission to reuse any of this content visit http://group.bmj.com/group/rights-licensing/permissions.

BMJ Case Report Fellows may re-use this article for personal use and teaching without any further permission.

Become a Fellow of BMJ Case Reports today and you can:

- Submit as many cases as you like

- Enjoy fast sympathetic peer review and rapid publication of accepted articles

- Access all the published articles

- Re-use any of the published material for personal use and teaching without further permission

For information on Institutional Fellowships contact consortiasales@bmjgroup.com

Visit casereports.bmj.com for more articles like this and to become a Fellow 